\title{
Weak Exhaustivity and Whether: A Pragmatic Approach
}

\author{
Elena Guerzoni \\ University of Southern California
}

\section{Introduction}

Recent studies on interrogatives indicate that some question embedding predicates (QEPs) cannot support strongly exhaustive inferences, contra Groenendijk and Stokhof (1982) (c.f. Berman 1991, Heim 1994, Sharvit 2002). Some verbs that support strongly exhaustive inferences are know, find out, and wonder. Among the predicates that can only support weakly exhaustive inferences we find verbs like surprise, disappoint, realize, and predict $n \%$ correctly.

Previous views on this problem encode the above distinction either in different lexical semantic properties (see Beck and Rullmann 1999 and Sharvit 2002) or in different selectional restrictions of different QEPs (see Guerzoni 2003), but provide no independent motivation for either.

This paper proposes a pragmatic account that improves on the existing proposals in two respects. On the one hand, it provides the independent motivation for the classification of different QEPs, which was missing from earlier approaches. On the other hand, it offers an understanding of a seemingly unrelated long lasting puzzle; that is the impossibility for predicates like surprise, disappoint, realize, anticipate etc. to embed whether-complements (c.f. Karttunen 1977, Lahiri 1991, Guerzoni 2003, Guerzoni \& Sharvit 2006). The remainder of this section briefly introduces the notions of weak and strong exhaustivity.

\subsection{The Weak vs. Strong Exhaustivity Distinction}

Groenendijk and Stokhof (1982) observe that QEPs like know support both weakly and strongly exhaustive inferences. An example of a weakly exhaustive inference is given in (1); an example of strongly exhaustive inference, in (2).

(1) Mary knows who was at the party last night.

John was at the party last night.

Mary knows that John was at the party last night.

I would like to thank Jon Gajewski, Martin Hackl, Irene Heim, and Danny Fox for generous and precious feedback, Barry Schein for remarks that helped me overcome my skepticism towards a pragmatic view of exhaustivity and the audience of SALT XVII for questions and comments. Thanks also to the editors of these proceedings, Tova Friedman and Masayuki Gibson. 
(2) Mary knows who was at the party last night. John wasn't at the party last night.

Mary knows that John wasn't at the party last night

In general, an attribution of weakly exhaustive knowledge to Mary relative to who was at the party last night would merely amount to (3), which attributes to Mary the belief that all those who where at the party were indeed at the party. Crucially, this alone is compatible with Mary mistakenly believing that someone was at the party who in fact wasn't.

(3) For every $x$ in the domain of quantification, if $x$ was at the party Mary knows that $\mathrm{x}$ was at the party.

An attribution of strong exhaustive knowledge, instead, amounts to (4) below, which is incompatible with the possibility of Mary mistakenly believing that someone was at the party, if (s)he wasn't.

(4) For every $\mathrm{x}$ in the domain of discourse, Mary knows whether $\mathrm{x}$ was at the party last night .

Another way Groenendijk and Stokhof illustrate strong exhaustivity is given in (5), which is a valid inference under the additional assumption that Mary is completely aware of what makes up the relevant domain of discourse (a.k.a. the Complete Awareness Assumption, Berman 1991).

Mary knows who was at the party last night.

Mary knows who wasn't at the party last night.

Under this second characterization, it is possible to show that predicates like wonder and ask, which unlike know, do not have a proposition embedding incarnation, can support strong exhaustive inferences.

(6) Mary wonders/asked who was at the party last night.

Mary wonders/asked who wasn't at the party last night.

While predicates like know, find out, remember, wonder, ask, inquire, etc. (can) support strongly exhaustive inferences, there is a subset of QEPs which have been argued to support only weakly exhaustive inferences. Among these verbs one finds 'emotive' factives (like surprise and disappoint) and 'epistemic' 
factives (like realize, predict $n \%$ correctly, anticipate). (C.f. Berman 1991, Lahiri 1991, Heim 1994, and Sharvit 2002).

Heim (1994) offers the following observation about surprise. Assume that for any proposition $p$, it surprises $x$ that $p$ amounts to asserting that $x$ expected not $p$ and that it surprises $x Q$ expresses the same relation, but between $\mathrm{x}$ and the proposition that is the complete true answer to Q. If question embedding surprise (Q-surprise) could receive a strongly exhaustive interpretation, Mary's past mistaken expectation relative to one absentee from the party should be sufficient to make the sentence in (7) true:

(7) It surprised Mary who was at the party last night.

In other words, if Q-surprise had a strongly exhaustive semantics, the following inference would be incorrectly predicted to be valid (under the background assumption that the relevant domain of discourse includes only Mark, Susan and Bill and that Mary is aware of this):

(8) Susan, and Bill were at the party, Mark wasn't.

Mary had expected Susan, Bill, but also Mark to be the party.

It surprised Mary who was at the party last night.

While the above inference is intuitively invalid, the inference in (9) is valid, thus suggesting that Q-surprise is only weakly exhaustive.

(9) Susan, and Bill were at the party, while Mark wasn't.

Mary had expected that Bill would not be at the party

It surprised Mary who was at the party last night.

Substituting negative expectations with 'negative' wishes, one can construct the same argument for disappoint.

Finally, Sharvit (2002) suggests that the unacceptability of examples like (10) indicates that also some epistemic factives such as predict $100 \%$ correctly are only weakly exhaustive (for similar arguments regarding realize and anticipate see Berman 1991, Beck \& Rullmann 1999, and Guerzoni \& Sharvit 2007):

(10) John didn't predict $100 \%$ correctly who would be admitted.

\#For example Bill wasn't admitted and John didn't predict that. 


\section{Previous Approaches}

Following Heim (1994) most existing approaches analyze QEPs as attitudes towards a complete (i.e. exhaustive) answer to the question they embed, but assume that there are two types of complete answers these verbs can refer to: the 'weakly exhaustive' answer, which is the proposition that is the semantically congruent true complete answer to the question in a given world; and the 'strongly exhaustive answer', that is the proposition that the weakly exhaustive answer as defined above is the complete answer to the question in that world. Assuming a Hamblin/Karttunen extension of questions (i.e. the set of propositions that count as possible instantial answers in a given world, which I abbreviate as "Q(w)" below), Heim (1994) defines these two notions of answer as follows:

a. For any question $\mathrm{Q}$ and world w: $\operatorname{ans}_{1}(\mathrm{Q})(\mathrm{w})=\cap\{\mathrm{p}: \mathrm{p} \in \mathrm{Q}(\mathrm{w}) \& \mathrm{w} \in \mathrm{p}\}$

b. For any question $\mathrm{Q}$ and world $\mathrm{w}$ :

$$
\operatorname{ans}_{2}(Q)(w)=\left\{w^{\prime}: \operatorname{ans}_{1}(Q)(w)=\operatorname{ans}_{1}(Q)\left(w^{\prime}\right)\right\}
$$

These two distinct notions of exhaustive answers are central to two current views on the distinction between predicates that can be strongly exhaustive (like know) and predicates that cannot (like surprise and realize) (c.f. Beck and Rullmann 1999 and Sharvit 2002). Specifically, these approaches, analyze the 'strongly exhaustive' vs. 'weakly exhaustive' distinction, as follows: weakly exhaustive QEPs denote attitudes towards $a s_{1}$, while strongly exhaustive predicates are viewed as attitudes towards ans 2 . Verbs which seemingly can but do not have to support strongly exhaustive readings are viewed as ambiguous between a lexical entry referring to ans ${ }_{1}$ and a lexical entry referring to ans 2 . Verbs like surprise are viewed as univocally denoting an attitude towards ans ${ }_{1}$, the weakly exhaustive answer.

The predictions are correct. For example, suppose that Bill and Sue and no one else called Mary on August 15, 2007 in the actual world (@), then in @, ans to the question who called Mary on August 15, 2007? is the proposition that Bill and Sue called her on that day, and knowing ans ${ }_{1}$ amounts to knowing this proposition. This knowledge is compatible with the mistaken belief that also Mark called Mary on August 15, 2007. For someone to know ans 2 to the question, instead, is to know that the proposition that Bill and Susan called on August 15, 2007 is the COMPLETE answer to the question who called Mary on 08/15.07 in (a. This knowledge is not compatible with mistaken beliefs about individuals who didn't call Mary on that day in @.

Although this view is descriptively adequate, it does not yet provide a principled explanation of the weak vs. strong distinction. This is so because it reduces the impossibility to support strongly exhaustive inferences (which I will 
refer to as the weak exhaustivity problem) to the impossibility to refer to ans $\mathrm{a}_{2}$, but offers no explanation of the latter. ${ }^{1}$

In addition, this view inevitably misses an important generalization: all and only univocally weak QEPs generally disallow whether-complements (Lahiri 1991, Guerzoni 2003, Guerzoni \& Sharvit 2006):

*It surprised Mary (/Mary realized) whether Bill called.

A theory where the only constraint on the predicates under discussion is that their lexical semantics cannot make reference to ans 2 cannot account for facts like (12), because nothing in this theory would prevent surprise or anticipate to embed whether questions under an ans ${ }_{1}$ semantics. Given this, such a theory would need to find an explanation for (12) that is independent from its explanation for the weak exhaustivity problem. In other words, under this view, the fact that the same class of verbs is subject to both the weak exhaustivity problem and to the constraint against whether complements would fall out as a mere coincidence.

However, there are very good reasons to believe that weak exhaustivity and the ban against whether complements are two sides of the same coin.

This is because when yes/no questions are concerned, the ans ${ }_{1}$ vs. ans 2 distinction is neutralized. Specifically, the ans $_{1}$ to a yes/no question is already its strongly exhaustive answer. Let us see why.

The possible answers to a yes/no question of the form whether $p$ are two mutually exclusive and jointly exhaustive propositions, that is $p$ and $\neg$ p. Since they are mutually exclusive (that is for every world only one out of $p$ or $\neg p$ is true), all the worlds where $p$ is true are worlds where $p$ is the COMPLETE true answer to whether $p\left(\mathrm{ans}_{1}\right)$ and vice versa. Thus the proposition $\mathrm{p}$ and the set of worlds where $\mathrm{p}$ is the complete true answer to whether $p$ are one and the same set. Given this, in every world $\mathrm{w}$ where $\mathrm{p}$ is true, $\mathrm{p}$ represents both ans $\mathrm{s}_{1}$ and ans $\mathrm{s}_{2}$ to the question whether $p$. (13) is a formal proof of this claim:

(13) For any world $w$ and proposition $\mathrm{p}$, such that $\mathrm{w} \in \mathrm{p}$,

a. $\operatorname{Ans}_{1}(\llbracket$ whether $p \rrbracket)(\mathrm{w})=\cap\{\mathrm{q}: \mathrm{q} \in(\llbracket$ whether $p \rrbracket)(\mathrm{w}) \& \mathrm{w} \in \mathrm{q}\}=$ $\cap\{\mathrm{q}: \mathrm{q} \in\{\mathrm{p}, \neg \mathrm{p}\} \& \mathrm{w} \in \mathrm{p}\}=\cap\{\mathrm{q}:(\mathrm{q}=\mathrm{p}$ or $\mathrm{q}=\neg \mathrm{p}) \& \mathrm{w} \in \mathrm{q}\}$ $=\cap\{\mathrm{q}: \mathrm{q}=\mathrm{p}\}=\cap\{\mathrm{p}\}=\mathrm{p}$

b. $\operatorname{Ans}_{2}(\llbracket$ whether $p \rrbracket)(\mathrm{w})=$ $\left\{\mathrm{w}^{\prime}: \operatorname{ans}_{1}(\llbracket\right.$ whether $p \rrbracket)(\mathrm{w})=\operatorname{ans}_{1}(\llbracket$ whether $\left.p \rrbracket)\left(\mathrm{w}^{\prime}\right)\right\}$ $=\left\{\mathrm{w}^{\prime}: \mathrm{p}=\operatorname{ans}_{1}(\llbracket\right.$ whether $\left.\mathrm{p} \rrbracket)\left(\mathrm{w}^{\prime}\right)\right\}=\left\{\mathrm{w}^{\prime}: \mathrm{w}^{\prime} \in \mathrm{p}\right\}=\mathrm{p}$

\footnotetext{
${ }^{1}$ The alternative view I proposed in Guerzoni (2003), which derived the weakly vs. strongly exhaustive distinction from different selectional properties of different QEPs, does not fare better in this respect (see footnote 3 ).
} 
The same holds for $\neg \mathrm{p}$ : if $\neg \mathrm{p}$ is true in a given world, then $\neg \mathrm{p}$ is both ans $_{1}$ and ans $_{2}$ to whether $p$ in that world. (The proof is analogous to the one in 13, and I leave it to the reader).

Finally, since $\mathrm{p}$ and $\neg \mathrm{p}$ are also jointly exhaustive (i.e. for every world $\mathrm{w}$ at least one out of $\mathrm{p}$ and $\neg \mathrm{p}$ has to be true) the following holds for any w and any $\mathrm{p}$ :

$$
\operatorname{ans}_{1}(\llbracket \text { whether } p \rrbracket)(\mathrm{w})=\operatorname{ans}_{2}(\llbracket \text { whether } p \rrbracket)(\mathrm{w})
$$

Given this, each possible answer to a whether question is per se already strongly exhaustive and therefore the inability of verbs like surprise and $\operatorname{predict}(n \%)$ correctly to embed such questions must be related to the incompatibility with strongly exhaustive answers these verbs exhibit when they embed $w h$-interrogatives. ${ }^{2}$

The aim of this paper is to provide a unified account for this general incompatibility.

\section{Outline of the Proposal}

The account I am about to illustrate derives both restrictions on weak QEPs from a systematic incompatibility between meaning and implicatures of any sentence in which one of these QEPs ends up expressing an attitude towards a strongly exhaustive answer (be it due to the presence of whether or to the reference to $\mathrm{ans}_{2}$ ).

Focusing for the time being on to the case of yes/no questions, let us see what the basic idea is.

We can start with the observation that each weak QEP comes in a proposition embedding incarnation (PE) as well and that any sentence where a QEP with a PE counterpart embeds a whether question (as in the examples in 15a and 16a below), has two more informative alternatives (15b, c and 16b, c) where its PE counterpart embeds the two possible answers to that question.

\footnotetext{
${ }^{2}$ In Guerzoni (2003), I phrased this latter general point in slightly different terms. Specifically, I proposed that strongly exhaustive interpretations are always the result of the presence of a

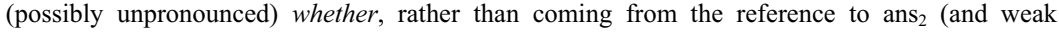
interpretations result from the absence of whether, accordingly). In fact, the denotation of a $w h$ question containing a hidden whether is, just like the denotation of simple yes/no question, inherently strongly exhaustive (i.e. its ans $_{1}$ is its strongly exhaustive answer). Within this perspective, the above generalization can be simply rephrased as a ban against whether complements under the QEPs under discussion. An explanation of why these QEPs in particular should be subject to such a restriction was left for further research. The pragmatic account suggested below turns out to be compatible with both a question based view, like the one I adopted in Guerzoni (2003), and with the answer based view discussed in this section.
} 
(15) a. * It surprised/disappointed Mary whether Susan was at the party.

b. It surprised/disappointed Mary that Susan was at the party

c. It surprised/disappointed Mary that Susan wasn't at the party.

(16) a. Mary knows whether Susan was at the party.

b. Mary knows that Susan was at the party

c. Mary knows that Susan wasn't at the party.

The general idea is that if the one knows which one or $(15 b)$ or $(15 c)$ is true, there is something intuitively very odd about asserting a sentence like (15a) instead. In fact this choice would be perceived to be inconsistent.

Formally, the utterance of any sentence where one of these QEPs embeds a whether question triggers the implicature that the speaker is uncertain about each more informative alternative. In the case of weak QEPs, the assertion and its presuppositions instead imply that the speaker is certain about one of the alternatives, thus contradicting the implicature. In the case of strong QEPs the uncertainty implicature will be shown to be compatible with assertion and presuppositions and therefore harmless. It is the presence vs. absence of this contradiction, I will argue, that accounts for the contrast between (15a) vs. (16a).

The distinctive property of weak QEPs that explains this difference is that they carry the presupposition that the speaker is informed about the true answer to the question they embed (Guerzoni and Sharvit 2007).

\section{Weak QEPs and whether}

\subsection{Speaker Factivity}

Guerzoni and Sharvit (2007) (G\&E henceforth) suggest that all weak QEPs carry the presupposition that the speaker knows the complete true answer to the question they embed and dub this property "speaker factivity" to distinguish it from "subject factivity", which is the presupposition that the attitude holder knows the true answer. ${ }^{3}$

The examples below show that two otherwise very similar predicates like find out and realize differ precisely this respect: Find out, which can be strongly exhaustive, can be felicitously used when the speaker doesn't know the answer to the embedded question. Realize, which is only weakly exhaustive, cannot be used in such circumstances.

\footnotetext{
${ }^{3}$ While G\&S already indicate that the unavailability of strongly exhaustive readings must be related to speaker factivity, they leave it as an open question what exactly the nature of this correlation is.
} 
(17) Context: Mary doesn't know who was at the party she missed the night before. Her friend John wasn't there either. Mary picks up the phone, calls John, and starts inquiring...

a. M: Hi John, so have you found out who was at the party?

b. M: \# Hi John, have you realized who was at the party?

c. J: No, sorry, I haven't yet found out who was there.

d. J: \# No sorry, I haven't yet realized who was there.

That this is a felicity condition rather than part of the assertion is confirmed by the fact that it is preserved in questions (as shown in 17b), and under negation (as shown in 17d).

G\&S suggest that emotive factives like surprise and disappoint come with the same presupposition. Indeed, native speakers find that there is something extremely odd about an utterance of any of the sentences in (18), if the speaker doesn't know who passed the exam.

(18) a. It will surprise/disappoint Bill who passed the exam.

b. Will it surprise Bill who passed the exam?

c. It is surprising/disappointing who passed the exam.

My informants' judgments relative to an utterance of (19), under the same circumstances, are less solid.

(19) It surprised/disappointed Bill who passed the exam.

Since at this time I have no explanation for this, I will adopt the assumption that also emotive factives are speaker factive and leave it as an open question what precisely is going on in cases like (19).

\subsection{Semantics and Pragmatics of "Realize Whether"}

This Section focuses on Q-realize, as a representative example of the class of epistemic factive weak QEPs, and proposes an explanation of how speaker factivity prevents these predicates from embedding whether complements.

As mentioned in Section 3, for every example such as (20a), there are two alternatives $(20 \mathrm{~b}, \mathrm{c})$, which asymmetrically entail it. 4
a. *John realized whether Mary passed the exam.
b. John realized that Mary passed the exam.
c. John realized that Mary didn't pass the exam.

\footnotetext{
${ }^{4}$ I assume here that the semantics of the question itself, being it the set of possible answers, is what makes there alternatives contextually available.
} 
In order to see that these examples do indeed stand in the above mentioned semantic relation, it is important to compare the two meanings of realize in its question embedding and proposition embedding incarnations (which I will refer to as Q-realize and p-realize, respectively).

Let us consider these two meanings in turn. We know from Section 4.1 that Q-realize comes with a speaker factivity presupposition. In addition, $x$ realized $Q$ appears to carry the presupposition that prior to the event time, $\mathrm{x}$ did not know the true answer to Q. ${ }^{5}$ Finally, $x$ realized $Q$ asserts that at the evaluation time $\mathrm{x}$ believes the true answer to the question.

In order to formally define the semantic contribution of Q-realize described above, I will adopt Kaplan's two step semantics, according to which each expression $\alpha$ has two levels of meaning: a "character", that is a function from contexts to intensions (I refer to this function with " $\llbracket \mathbb{\rrbracket}$ "), and, in any given

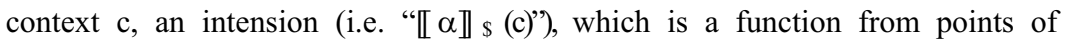
evaluation (i.e. pairs of worlds and times, such as $\left\langle\mathrm{w}_{\mathrm{i}}, \mathrm{t}_{\mathrm{i}}\right\rangle$ ) to truth values. In addition I will assume that each utterance context $\mathrm{c}$ is a triple $\left\langle\mathrm{w}_{\mathrm{c}}, \mathrm{t}_{\mathrm{c}}, \mathrm{s}_{\mathrm{c}}\right\rangle$, such that $s_{c}$ is the speaker in the world $w_{c}$ at the time $t_{c}$. Given this, we can define the lexical entry for Q-realize as in (21) below. ${ }^{6}$

(21) For every individual $\mathrm{x}$, context $\mathrm{c}$ ( such that $\mathrm{c}=\mathrm{w}_{\mathrm{c}}, \mathrm{t}_{\mathrm{c}}, \mathrm{s}_{\mathrm{c}}>$ ), point of evaluation $<\mathrm{w}_{\mathrm{i}}, \mathrm{t}_{\mathrm{i}}>$ and set of propositions $\mathrm{Q}$ :

a. 【Q-realize $\rrbracket_{\$}(\mathrm{c})\left(<\mathrm{w}_{\mathrm{i}}, \mathrm{t}_{\mathrm{i}}>\right)(\mathrm{Q})(\mathrm{x})$ is defined iff

(i) in $\mathrm{w}_{\mathrm{c}}$, at $\mathrm{t}_{\mathrm{c}}, \mathrm{s}_{\mathrm{c}}$ believes ans $(\mathrm{Q})\left(\mathrm{w}_{\mathrm{c}}\right)$ and

Speaker Factivity

(ii) For all $\mathrm{t}^{\prime}<\mathrm{t}_{\mathrm{i}}$, it is not the case that $x$ believes ans $(\mathrm{Q})\left(\mathrm{w}_{\mathrm{c}}\right)$ at $\mathrm{t}^{\prime}$.

b. If defined, $\llbracket \mathrm{Q}$-realize $\rrbracket_{\$}(\mathrm{c})\left(<\mathrm{w}_{\mathrm{i}}, \mathrm{t}_{\mathrm{i}}>\right)(\mathrm{Q})(\mathrm{x})=1$ iff

$x$ believes ans $(\mathrm{Q})\left(\mathrm{w}_{\mathrm{c}}\right)$ in $\mathrm{w}_{\mathrm{i}}$ at $\mathrm{t}_{\mathrm{i}}$

Turning now to $\mathrm{p}$-realize, $x$ realized $p$ carries two presuppositions as well; that $\mathrm{p}$ is true (i.e. it is factive) and that $\mathrm{x}$ did not know the proposition expressed by $p$ at some time prior to the evaluation time; ${ }^{7}$ the assertion is that $\mathrm{x}$ knows the

\footnotetext{
${ }^{5}$ That this component of the meaning of p-realize is presupposed rather than asserted is confirmed by the fact that it is preserved under negation and in questions:

(i) a. Bill will realize who is at the party. $\quad \approx>$ Bill doesn't know who was at the party

b. Bill won't realize who is at the party $\approx>$ Bill doesn't know who was at the party.

c. Will Bill realize who was at the party? $\approx>$ Bill doesn't know who was at the party
}

\footnotetext{
${ }^{6}$ Since in the case of polar questions the $a_{1} s_{1} /$ ans $_{2}$ distinction is irrelevant, I left the ans operator in the above lexical entry unmarked assuming that it can stand for any of ans or $_{\text {ans }}$. In the discussion of wh-complements below the distinction will become relevant, and this lexical entry will be modified as to refer to either $\mathrm{ans}_{2}$ or $\mathrm{ans}_{1}$, depending on the reading to be captured.

${ }^{7}$ That this is a presupposition is confirmed by the fact that it is preserved under negation and in questions:

(i) a. Bill won't realize that I was at the party $\approx>$ Bill doesn't know that I was at the party

b. Will Bill realize that I was at the party? $\approx>$ Bill doesn't know that I was at the party
} 
proposition expressed by $p$ at the evaluation time. A formal definition of the contribution of p-realize is given in (22).

(22) For every individual $\mathrm{x}$, context $\mathrm{c}$, point of evaluation $\left.<\mathrm{w}_{\mathrm{i}}, \mathrm{t}_{\mathrm{i}}\right\rangle$, and proposition $\mathrm{p}$ :

a. $\llbracket \mathrm{p}$-realize $\rrbracket_{\$}(\mathrm{c})\left(<\mathrm{w}_{\mathrm{i}}, \mathrm{t}_{\mathrm{i}}>\right)(\mathrm{p})(\mathrm{x})$ is defined iff

(i) $\mathrm{p}\left(<\mathrm{w}_{\mathrm{c}}, \mathrm{t}_{\mathrm{c}}>\right)=1$ and

Factivity

(ii) For all $\mathrm{t}^{\prime}<\mathrm{t}_{\mathrm{i}}$, it is not the case that $\mathrm{x}$ believes $\mathrm{p}$ at $\mathrm{t}^{\prime}$.

b. If defined, 【p-realize $\rrbracket_{\$}(\mathrm{c})\left(<\mathrm{w}_{\mathrm{i}}, \mathrm{t}_{\mathrm{i}}>\right)(\mathrm{p})(\mathrm{x})=1$ iff $x$ believes $\mathrm{p}$ in $\mathrm{w}_{\mathrm{i}}$ at $\mathrm{t}_{\mathrm{i}}$

It is evident that, because $\operatorname{ans}(\mathrm{Q})\left(\mathrm{w}_{\mathrm{c}}\right)$ is a proposition, the second presupposition and the assertion of Q-realize and p-realize are analogous. The only significant difference between the two verbs is that while Q-realize is speaker factive, p-realize is factive simpliciter.

Let us see how this affects the semantic relation between the sentences in (20). First, in a given context c, (20a) presupposes (23b) and asserts (23c).

(23) a. *John realized whether Mary passed the exam.

b. Presuppositions:

(i) the speaker knows whether Mary passed the exam in $\mathrm{w}_{\mathrm{c}}$

(ii) before the time of the event, John didn't know whether Mary passed the exam.

c. Assertion:

At the event time John knows whether Mary passed the exam

Second, assertions and presuppositions of (20b) and (20c) in c are those given in (24) and (25) respectively.

(24) a. John realized that Mary passed the exam.

b. Presuppositions:

(i) Mary passed the exam in $\mathrm{w}_{\mathrm{c}}$

(ii) Before the event time John didn't know that Mary passed the exam

c. Assertion:

At the event time John knows that Mary passed the exam

(25) a. John realized that Mary didn't pass the exam.

b. Presuppositions:

(i) Mary didn't pass the exam in $\mathrm{w}_{\mathrm{c}}$

(ii) Before the e. time John didn't know that Mary didn't pass the exam

c. Assertion:

At the event time John knows that Mary didn't pass the exam 
It follows that (24a) and (25a) each asymmetrically entails (23a). Here is why.

First, whenever (24a) is true (and therefore defined) the following holds: (i) it is common knowledge in the utterance context that Mary passed the exam and that John didn't know this, and (ii) John knows at the event time that Mary passed. Given (i), it follows that (iii) the speaker must know whether Mary passed, and it must be the case that, at some time before the event time, John didn't know whether she did. Given (ii), it follows that (iv) John knows at the event time whether Mary passed. Given (iii) and (iv), (23a) is defined and true. Therefore whenever (24a) is true, so is (23a).

Second, the same relation holds between (25a) and (23a). If (25a) is defined the common ground entails that Mary didn't pass the exam and John used to be unaware of this, thus (23a) is defined as well. Moreover, the truth of (25a) entails that at the event time John knows whether Mary passed, which makes (23a) true.

Finally (23a) entails neither (24a) nor (25a), because (23a) can be true in worlds where Mary passed the exam, and thus where (25a) is undefined; or in worlds where Mary didn't pass, and thus where is (24a) undefined.

This semantic relation holds in general: If $p$ expresses a proposition and $\neg$ $p$ its negation, each sentence of the form $x$ realized that $p$ and $x$ realized that $\neg p$, asymmetrically entails the sentence $x$ realized whether $p$.

Given this, we predict that any utterance of $x$ realized whether $p$ will generate the two following primary quantity implicatures: (i) the speaker fails to believe $x$ realized that $p$ and (s)he fails to believe that $x$ realized that $\neg p$. In (26) I illustrate these two implicatures by employing Gazdar's certainty operator $\mathrm{K}$ (see Garzdar 1979). ${ }^{8}$
a. $\neg \mathrm{K} x$ realized that $p$
b. $\neg \mathrm{K} x$ realized that $\neg p$

Notice that these two implicatures are perfectly compatible with each other. But let us see if they are compatible with the meaning and presuppositions of the utterance that triggers them. In the discussion below I will use the following abbreviations: I will use $R(p), R(\neg p)$, and $R$ (whether $p$ ), to refer to $x$ realized that $p$, $x$ realized that $\neg p$, and $x$ realized whether $p$ respectively.

${ }^{8}$ I follow Sauerland 2004 and call these implicatures "primary", as to distinguish them from the "secondary" implicatures in (i), which follow from the primary implicatures only under the assumption that the speaker has an opinion relative to the truth of $x$ realized that $p$.

(i) $\quad \mathrm{K} \neg x$ realized that $p, \mathrm{~K} \neg x$ realized that $\neg p$

A difference between primary and secondary implicatures that is fundamental to my analysis is that while secondary implicatures can be suspended when they contradict the assertion, primary implicatures cannot (see Sauerland 2004). 
The assertion $R$ (whether $p$ ) entails (27a), i.e. that the speaker is certain that either $R(p)$ or $R(\neg p)$ is true, whichever is defined. Moreover, speaker factivity guarantees that the speaker also knows whether $p$ is true or not. It follows that (s)he knows which one of $R(p)$ or $R(\neg p)$ is defined. ${ }^{9}$ Given this, a cooperative speaker can utter $R$ (whether $p$ ) only in contexts where either (s)he is certain that $R(p)$ is true or (s)he is certain that $R(\neg p)$ is. Thus (27b) holds as well.
a. $\mathrm{K}(R(p) \vee R(\neg p))$
b. $\mathrm{K} R(p) \vee \mathrm{K} R(\neg p)$

However, (27b) and the implicatures we derived in (26) are incompatible.
a. $\mathrm{K}(R(p) \vee \mathrm{K} R(\neg p))$
b. $\neg \mathrm{K} R(p) \wedge \neg \mathrm{K} R(\neg p)$

$\perp$

Given this, any utterance like John realized whether Mary passed the exam, when defined, systematically triggers primary implicatures that are incompatible with its very meaning. Since these primary implicatures cannot be suspended (see Sauerland 2004 and footnote 8) the contradiction cannot be avoided or repaired. I propose that the unacceptability of (20a) follows from this systematic impossibility for any speaker to utter this sentence without incurring in a contradiction.

This proposal makes the following additional prediction. Notice that in the absence of speaker factivity, the inference from (27a) to (27b) would be invalid, and, since (27a) and the implicatures in (26) are mutually compatible, no contradiction would emerge. Therefore this account correctly predicts that QEPs that are not speaker factive (like know) can embed whether complements.

\subsection{Semantics and Pragmatics of "Surprise Whether"}

As mentioned in Section 1, besides epistemic factives, the class of QEPs that cannot embed whether-questions includes also emotive factives like surprise and disappoint. This section shows that the proposal I made in Section 4.2 can be straightforwardly applied to emotive factives as well. I will discuss only a representative case of this latter class, namely Q-surprise, but the analysis extends to the other predicates of this class as well.

Just like in the case of Q-realize, a sentence in which surprise embeds a whether-question has two stronger alternatives: the two sentences where p-

\footnotetext{
${ }^{9}$ For the sake of simplicity, I leave aside the second presupposition of $S(p)$ (i.e. that $\mathrm{x}$ knows $\mathrm{p}$ ) and of $S(\neg p)$ (i.e. that $\mathrm{x}$ knows that $\neg \mathrm{p}$ ). This is not going to affect the proposal.
} 
surprise embeds one of the two possible answers to the question. Here is an example:

(29) a. *It surprised John whether Mary passed the exam.

b. It surprised John that Mary passed the exam

c. It surprised John that Mary didn't pass the exam.

In order to see why the p-embedding alternatives are stronger than the Qembedding case, let us compare the meanings of Q-surprise and p-surprise.

Recall from Section 1.1 that Q-surprise asserts that prior to the event time the subject expected the negation of the true answer to the embedded question. In addition, Q-surprise carries two presuppositions: the presupposition that the speaker knows the true answer to the embedded question ("speaker factivity"), and the presupposition that at the event time also the subject knows this answer ("subject factivity"). ${ }^{10}(30)$ provides a formal definition of this meaning.

(30) For every individual $\mathrm{x}$, context $\mathrm{c}$, and point of evaluation $\left\langle\mathrm{w}_{\mathrm{i}}, \mathrm{t}_{\mathrm{i}}>\right.$ :

a. 【Q Q-surprise $\rrbracket_{\mathrm{S}}(\mathrm{c})\left(<\mathrm{w}_{\mathrm{i}}, \mathrm{t}_{\mathrm{i}}>\right)(\mathrm{Q})(\mathrm{x})$ is defined iff

(i) $\mathrm{s}_{\mathrm{c}}$ believes ans $(\mathrm{Q})\left(\mathrm{w}_{\mathrm{c}}\right)$

Speaker factivity

(ii) at $t_{i}, x$ believes ans $(Q)\left(w_{c}\right)$

b. If defined, 【Q-surprise $\rrbracket_{\$}(\mathrm{c})\left(<\mathrm{w}_{\mathrm{i}}, \mathrm{t}_{\mathrm{i}}>\right)(\mathrm{Q})(\mathrm{x})=1$ iff

There is a $\mathrm{t}^{\prime}<\mathrm{t}_{\mathrm{i}}$ such that $\mathrm{x}$ believes $\neg \operatorname{ans}(\mathrm{Q})\left(\mathrm{w}_{\mathrm{c}}\right)$ at $\mathrm{t}^{\prime}$

P-surprise asserts that prior to the event time the subject expected the negation of the embedded proposition and carries the presuppositions that the embedded proposition is true and that at the event time the subject believes it. Thus the lexical entry of p-surprise looks roughly as follows:

(31) For every individual $\mathrm{x}$, context $\mathrm{c}$, and point of evaluation $\left\langle\mathrm{w}_{\mathrm{i}}, \mathrm{t}_{\mathrm{i}}\right\rangle$ :

a. 【p-surprise $\rrbracket_{\$}(\mathrm{c})\left(<\mathrm{w}_{\mathrm{i}}, \mathrm{t}_{\mathrm{i}}>\right)(\mathrm{p})(\mathrm{x})$ is defined iff

(i) $\mathrm{p}\left(\mathrm{w}_{\mathrm{c}}\right)=1$

Factivity

(ii) at $t_{i}, x$ believes $p$

b. If defined, 【p-surprise $\rrbracket_{\$}(\mathrm{c})\left(<\mathrm{w}_{\mathrm{i}}, \mathrm{t}_{\mathrm{i}}>\right)(\mathrm{p})(\mathrm{x})=1$ iff

There is a $\mathrm{t}^{\prime}<\mathrm{t}_{\mathrm{i}}$ such that $\mathrm{x}$ believes $\neg \mathrm{p}$ at $\mathrm{t}^{\prime}$

\footnotetext{
${ }^{10}$ The fact that this component of the meaning of Q-surprise is preserved as such under negation and in questions, confirms that it is a presupposition.

(i) It surprised Mary who passed the exam. $\quad \approx>$ Mary knows who passed the exam

It didn't surprise Mary who passed the exam $\approx>$ Mary knows who passed the exam

Did it surprise Mary who passed the exam? $\approx>$ Mary knows who passed the exam

This is true also for disappoint and other emotive factive QEPs, while it is not for epistemic QEPs (factive or non factive) such as Q-realize, Q-know etc.
} 
Although (30) and (31) are very different from the lexical entries of Qrealize and $\mathrm{p}$-realize, they stand in the same relation the latter two entries were shown to stand in; that is, because ans $(\mathrm{Q})\left(\mathrm{w}_{\mathrm{c}}\right)$ is a proposition, the assertions and the subject factivity presuppositions of Q-surprise and p-surprise are fully analogous. The only substantial difference between the two predicates is that the former is speaker factive and the latter is factive simpliciter. Given this, we expect the relation between the p-embedding examples and the Q-embedding example in (29) to be the same as the relation between the parallel cases involving realize: each of (29b) and (29c) asymmetrically entail (29a), and, in general, any sentence of the form It surprised $x$ that $p$ or It surprised $x$ that $\neg p$ (which I will abbreviate as $S(p)$ and $S(\neg p)$, respectively) asymmetrically entails the corresponding sentence It surprised $x$ whether $p$, which I will abbreviate as $S$ (whether $p$ ).

I leave it to the reader to verify that the two lexical entries support these prediction and turn directly to showing why an utterance of $S$ (whether $p$ ) in any context where it would be felicitous, leads to a contradiction.

Since $S(p)$ and $S(\neg p)$ are stronger than $S$ (whether $p$ ), an utterance of $S$ (whether $p$ ) generates the primary implicatures listed below in (32a). In addition, the assertion of $S$ (whether $p$ )entails (32b) and, following the same reasoning as in Section 4.2., (32b) together with speaker factivity leads to (32c).

$$
\begin{array}{ll}
\text { a. } & \neg \mathrm{K} S(p), \neg \mathrm{K} S(\neg p) \\
\text { b. } & \mathrm{K}(S(p) \vee S(\neg p)) \\
\text { c. } & \mathrm{K} S(p) \vee \mathrm{K} S(\neg p)
\end{array}
$$

What we have arrived at is totally parallel to what we derived in the case of realize, and just like in that case, (32c), together with the primary implicatures in $(32 a)$, leads to a contradiction. Here is why.

$$
\begin{aligned}
& \mathrm{K}(S(p) \vee \mathrm{K} S(\neg p)) \\
& \neg \mathrm{K} S(p) \wedge \neg \mathrm{K} S(\neg p)
\end{aligned}
$$

$\perp$

\section{Weak vs. Strong Exhaustivity}

The question that remains to be addressed is why the QEPs under discussion cannot receive strongly exhaustive interpretations (i.e. the problem of weak exhaustivity). This section illustrates how the account just presented can be extended to this problem. Due to space limitations, I will concentrate on Qsurprise.

Following the same line of reasoning adopted above, I start from the observation that also when Q-surprise embeds a wh-question (e.g. 34a) there are a 
number of stronger alternatives to the sentence involving p-surprise. Specifically, these alternatives are twice as many as there are individuals in the relevant domain of discourse minus one. ${ }^{11}$ If, for simplicity, we assume a small domain, say a domain containing only Bill and John, the alternatives to (34a) are (34a, b, c, and d):

(34) a. It surprised Mary who passed the exam.

b. It surprised Mary that John passed the exam and Bill didn't.

c. It surprised Mary that John and Bill passed the exam.

d. It surprised Mary that John didn't pass the exam and Bill did.

For the sake of the argument, let us now assume that (34a) could receive a strongly exhaustive reading. In order to capture this, the lexical entry of Qsurprise proposed in Section 4.3 needs to be slightly modified as to make reference to $a_{2} s_{2}$ (see footnote 6). The result is (35) below.

(35) For every individual $\mathrm{x}$, context $\mathrm{c}$, and point of evaluation $\left\langle\mathrm{w}_{\mathrm{i}}, \mathrm{t}_{\mathrm{i}}>\right.$ :

a. 《Q-surprise $\rrbracket_{\$}(\mathrm{c})\left(<\mathrm{w}_{\mathrm{i}}, \mathrm{t}_{\mathrm{i}}>\right)(\mathrm{Q})(\mathrm{x})$ is defined iff

(i) in $\mathrm{w}_{\mathrm{c}}$, at $\mathrm{t}_{\mathrm{c}}, \mathrm{s}_{\mathrm{c}}$ believes ans $2(\mathrm{Q})\left(\mathrm{w}_{\mathrm{c}}\right)$ and

Speaker Factivity

(ii) $x$ believes $\operatorname{ans}_{2}(\mathrm{Q})\left(\mathrm{w}_{\mathrm{c}}\right)$ in $\mathrm{w}_{\mathrm{i}}$ at $\mathrm{t}_{\mathrm{i}}$

b. If defined, $\llbracket \mathrm{Q}$-surprise $\rrbracket_{\mathrm{S}}(\mathrm{c})\left(<\mathrm{w}_{\mathrm{i}}, \mathrm{t}_{\mathrm{i}}>\right)(\mathrm{Q})(\mathrm{x})=1$ iff

For all $\mathrm{t}^{\prime}<\mathrm{t}_{\mathrm{i}}, x$ believes $\neg \operatorname{ans}_{2}(\mathrm{Q})\left(\mathrm{w}_{\mathrm{c}}\right)$ at $\mathrm{t}^{\prime}$.

Due to space limitations, I leave it to the reader to verify that this lexical entry and the lexical entry for p-surprise given in Section 4.3 correctly lead to the prediction that (34b) and (34c) and (34d) each asymmetrically entail (34a). and that, in general, if the relevant domain is the set $\{\mathrm{John}, \mathrm{Bill}\}$, each sentence of the form It surprised $x$ that John passed the exam and Bill didn't, It surprised $x$ that John and Bill passed the exam, and It surprised $x$ that John didn't pass the exam and Bill did (which I will abbreviate as $S(J \& \neg B), S(J \& B), S(B \& \neg J)$, respectively) asymmetrically entails It surprised $x$ who passed the exam (which I will abbreviate as $S$ (who $P$ )).

Given this, any utterance of $S$ (who $P$ ) generates the ignorance implicatures listed in (36a), while its assertive component entails (36b). In addition, speaker factivity relative to ans ${ }_{2}$ amounts to the condition that the speaker knows whether John passed the exam and whether Bill did, that is (36c).
a. $\neg \mathrm{K} S(J \& \neg B), \neg \mathrm{K} S(J \& B), \neg \mathrm{K} S(B \& \neg J)$
b. $\mathrm{K}(S(J \& \neg B) \vee S(J \& B) \vee S(B \& \neg J))$

\footnotetext{
${ }^{11} \mathrm{I}$ assume that Mary realized that no one passed the exam is automatically excluded as an alternative to (34a), because (34a) carries the additional presupposition that someone passed the exam.
} 
c. $(\mathrm{K} J \vee \mathrm{K} \neg J) \wedge(\mathrm{K} B \vee \mathrm{K} \neg B)$

(36b) and (36c), in turn, entail (37a). ${ }^{12}$ However, (37a) is evidently incompatible with the conjunction of the primary implicatures, i.e. with (37b).

a. $\mathrm{K} S(J \& \neg B) \vee \mathrm{K} S(J \& B) \vee \mathrm{K} S(B \& \neg J)$

b. $\neg \mathrm{K} S(J \& \neg B) \wedge \neg \mathrm{K} S(J \& B) \wedge \neg \mathrm{K} S(B \& \neg J)$

${ }^{12}$ Here is a formal proof of the claim that (36b) and (36c) entail (37a).

1. $\mathrm{K}(S(J \& \neg B) \vee S(J \& B) \vee S(B \& \neg J))$ $\mathrm{K} \mathrm{J}$

$\mathrm{K}(S(J \& \neg B) \vee S(J \& B))$

2. $\mathrm{K}(S(J \& \neg B) \vee S(J \& B) \vee S(B \& \neg J))$ $\mathrm{K} \neg \mathrm{J}$

$\mathrm{K} S(B \& \neg J)$

3. $\mathrm{K}(S(x, J \& \neg B) \vee S(J \& B) \vee S(B \& \neg J))$

$\mathrm{K} \mathrm{J} \vee \mathrm{K} \neg \mathrm{J}$

$\mathrm{K}(S(J \& \neg B) \vee S(J \& B)) \vee \mathrm{K} S(B \& \neg J)$

4. $\mathrm{K}(S(J \& \neg B) \vee S(J \& B) \vee S(B \& \neg J))$

$\mathrm{K} \mathrm{B} \vee \mathrm{K} \neg \mathrm{B}$

$B$

3)

$\mathrm{K}(S(J \& B) \vee S(B \& \neg J)) \vee \mathrm{K} S(J \& \neg B)$

5. $\mathrm{K}(S(J \& \neg B) \vee S(J \& B) \vee S(B \& \neg J))$

$(\mathrm{K} J \vee \mathrm{K} \neg J) \wedge(\mathrm{K} B \vee \mathrm{K} \neg B)$

$[\mathrm{K}(S(J \& \neg B) \vee S(J \& B)) \vee \mathrm{K} S(B \& \neg J)] \wedge[\mathrm{K}(S(J \& B) \vee S(B \& \neg J)) \vee \mathrm{K} S(J \& \neg B)]$ (from $3 \& 4)$

6. Assume the following abbreviations:

$\mathrm{A}=S(J \& \neg B), \mathrm{B}=S(J \& B), \mathrm{C}=S(B \& \neg J)$

7. Given 6, what remains to be proven is the following equivalence:

$[\mathrm{K}(\mathrm{A} \vee \mathrm{B}) \vee \mathrm{KC}] \wedge[\mathrm{K}(\mathrm{B} \vee \mathrm{C}) \vee \mathrm{KA}]=\mathrm{KA} \vee \mathrm{KB} \vee \mathrm{KC}$

(NB: (i) $S(J \& \neg B), S(J \& B), S(B \& \neg J)$ are mutually exclusive, thus any conjunction of $\mathrm{A}, \mathrm{B}$,

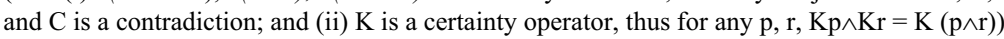

$[K(A \vee B) \vee K C] \wedge[K(B \vee C)] \vee K A]=[[K(A \vee B) \vee K C] \wedge K(B \vee C)] \vee[[K(A \vee B) \vee K C] \wedge K A]$

$=[K(A \vee B) \wedge K(B \vee C)] \vee[K C \wedge K(B \vee C)] \vee[K(A \vee B) \wedge K A] \vee[K C \wedge K A]$

$=[K((A \vee B) \wedge(B \vee C))] \vee[K(C \wedge(B \vee C))] \vee[K((A \vee B) \wedge A)] \vee[K(C \wedge A)]$

$=[K((A \vee B) \wedge(B \vee C))] \vee[K((C \wedge B) \vee(C \wedge C)] \vee[K(((A \wedge A) \vee(B \wedge A)]$

$=[K((A \vee B) \wedge B)) \vee((A \vee B) \wedge C)] \vee K C \vee K A$

$=[K((A \wedge B) \vee(B \wedge B))] \vee K C \vee K A$

$=\mathrm{KB} \vee \mathrm{KC} \vee \mathrm{KA}$

Q.E.D. 
It is this result, I propose, that makes a strongly exhaustive interpretation unavailable for Q-surprise.

Importantly, this account predicts that a weakly exhaustive interpretation of (34)a does not incur in the same contradiction. Since the lexical entry of Qsurprise that generates a weak interpretation refers to ans $\mathrm{s}_{1}$, under such a reading of (34)a, speaker factivity simply amounts to (38a) below, instead of (36c) above. What follows from (38a) together with the entailment of assertion repeated in (38b), is (38c), which is evidently compatible with all the ignorance implicatures of the sentence Mary realized who passed the exam (repeated in 39 below).

$$
\begin{aligned}
& \text { a. } \mathrm{K} \mathrm{J} \vee \mathrm{KB} \vee \mathrm{K}(\mathrm{B} \wedge \mathrm{J}) \\
& \text { b. } \mathrm{K}(S(J \& \neg B) \vee S(J \& B) \vee S(B \& \neg J))
\end{aligned}
$$

c. $\mathrm{K}(S(J \& \neg B) \vee S(J \& B)) \vee \mathrm{K}(S(J \& B) \vee S(B \& \neg J)) \vee \mathrm{K}(S(J \& B))$

$$
\neg \mathrm{K} S(J \& \neg B) \wedge \neg \mathrm{K} S(J \& B) \wedge \neg \mathrm{K} S(B \& \neg J)
$$

Finally, notice that without speaker factivity, (37a) would not follow, and since the implicatures in (36a) are compatible with each other and with the assertion, no contradiction would arise. Given this, the account outlined above leads us to a second desirable prediction: predicates that are not speaker factive, like know and find out can receive strongly exhaustive readings.

One potentially problematic case remains, that is the case where the speaker attributes to him or herself knowledge relative to a question

I know who passed the exam.

In this case what the speaker asserts entails that (s)he knows one of the stronger alternatives of the form $I$ know $p$, where $p$ denotes one of the possible complete answers to the embedded questions. Therefore, the assertion here should play the same role as speaker factivity above and, as a result, we should predict that (40) should not have a strongly exhaustive interpretation, contrary to our intuitions.

It is known, however, that self attitude attributions are peculiar in many ways. In this particular case, for example, my intuition is that the speaker's choice of uttering (40), instead of its true stronger alternative, is felicitous only in contexts where what is relevant is not so much the answer to the embedded question, but the identity of those who know about it. If this renders the stronger alternative irrelevant, then no implicature should arise. However, I have the impression that it is harder to express somebody's mistaken expectations (with surprise) or past ignorance (with realize), if the content of this ignorance or these expectations is irrelevant. This said, I will have to leave a fully satisfactory understanding of (40) for further research. 


\section{Conclusions}

This paper shows that when speaker factive QEPs embedded whethercomplements or refer in their semantics to a strongly exhaustive answer, the resulting meaning and implicatures are incompatible.

Therefore, since epistemic factives like realize and predict \%correctly are speaker factive and under the assumption that emotive factives like surprise and disappoint are speaker factive too, the paper provides a unified account for their lack of strongly exhaustive readings and their inability to embedding whether complements. Since QEPs like know, ask and find out are not speaker factive, this account correctly predicts that they can support strongly exhaustive readings and can embed whether-complements.

\section{References}

Beck, Sigrid and Hotze Rullmann: 1999, 'A Flexible Approach to Exhaustivity in Questions', Natural Language Semantics 7, 249-298.

Berman, Stephen R.: 1991, On the Semantics and Logical Form of WH-clauses. Doctoral Dissertation, UMASS Amherst. GLSA, Amherst.

Gazdar, Gerald: 1979, Pragmatics: Implicature, Presupposition and Logical Form. Academic Press, New York.

Guerzoni, Elena: 2003, Why 'Even' Ask? On the Pragmatics of Questions and the Semantics of Answers. Doctoral Dissertation, MIT.

Guerzoni, Elena and Yael Sharvit: 2007, 'A Question of Strength: On NPIs in Interrogative Clauses', Linguistics and Philosophy 30.

Groenendijk, Jeroen and Martin Stokhof: 1982, 'Semantic Analysis of WhComplements', Linguistics and Philosophy 5(2), 175-233.

Heim, Irene : 1994, 'Interrogative Semantics and Karttunen's Semantics of Know', Proceedings of IATL 1, 128-144.

Karttunen, Lauri, 1977, 'Syntax and Semantics of Questions', Linguistics and Philosophy 1.3, 3-44.

Lahiri, Utpal, 1991, Embedded Interrogatives and Predicates that Embed Them, Doctoral Dissertation, MIT. Distributed by MITWPL.

Sauerland, Uli: 2004, Linguistics and Philosophy 27, 367-391.

Sharvit, Yael, 2002, 'Embedded Questions and De Dicto Readings', Natural Language Semantics 10, 97-123. 